\title{
Ensemble meteorological reconstruction using circulation analogues of 1781-1785
}

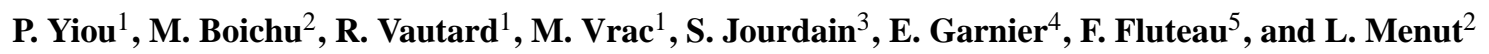 \\ ${ }^{1}$ Laboratoire des Sciences du Climat et de l'Environnement, CEA-CNRS-UVSQ \& IPSL - UMR8212, \\ CE Saclay l'Orme des Merisiers, 91191 Gif-sur-Yvette, France \\ ${ }^{2}$ Laboratoire de Météorologie Dynamique, UMR8539 X-ENS-UPMC \& IPSL, Ecole Polytechnique, 91128 Palaiseau, France \\ ${ }^{3}$ DClim, Météo France, 42 Avenue G. Coriolis, 31057 Toulouse, France \\ ${ }^{4}$ Institut Universitaire de France and Centre de Recherche d'Histoire Quantitative, CNRS - UMR6583 Université de Caen, \\ 14032 Caen, France \\ ${ }^{5}$ Institut de Physique du Globe, UMR7154, Sorbonne Paris Cité, 1 rue Jussieu, 75238 Paris, France
}

Correspondence to: P. Yiou (pascal.yiou@1sce.ipsl.fr)

Received: 1 August 2013 - Published in Clim. Past Discuss.: 6 September 2013

Revised: 12 February 2014 - Accepted: 10 March 2014 - Published: 24 April 2014

\begin{abstract}
This paper uses a method of atmospheric flow analogues to reconstruct an ensemble of atmospheric variables (namely sea-level pressure, surface temperature and wind speed) between 1781 and 1785 . The properties of this ensemble are investigated and tested against observations of temperature. The goal of the paper is to assess whether the atmospheric circulation during the Laki volcanic eruption (in 1783) and the subsequent winter were similar to the conditions that prevailed in the winter 2009/2010 and during spring 2010. We find that the 3 months following the Laki eruption in June 1783 barely had analogues in 2010. The cold winter of 1783/1784 yielded circulation analogues in 2009/2010. The reconstructed surface temperature over land bears significant correlations with local observations, although the amplitude of the reconstruction is weaker.
\end{abstract}

\section{Introduction and motivation}

The synoptic variability of the atmospheric circulation during the past centuries has been extensively studied from early instrumental records and proxy reconstructions (Cook et al., 1998; Jones et al., 1999; Luterbacher et al., 2002; Jacobeit et al., 2003). Such studies have attempted to reconstruct one trajectory of the climate system, giving sometimes loose boundary and initial conditions. It is striking that very few reconstructions of the atmospheric circulation over the
North Atlantic agree on periods preceding AD 1850 (Souriau and Yiou, 2001), mainly because of the lack of geographical constraints. Indeed, such reconstructions rely on one or two proxy records (Appenzeller et al., 1998; Cook et al., 1998; Luterbacher et al., 1999), while the North Atlantic circulation spatial structure exhibits a complexity that can hardly be captured by just two locations (e.g. Hurrell et al., 2003; Kimoto and Ghil, 1993; Michelangeli et al., 1995; Jacobeit et al., 2003). Hence it can be argued that it is necessary to obtain ensembles of reconstructed trajectories so that the uncertainty of reconstructions can be assessed.

Ensembles of reanalyses for the past two centuries have been proposed by Compo et al. (2011). Such exercises allow sampling this meteorological uncertainty (Palmer, 2002), which is connected to the chaos of atmospheric variability (Lorenz, 1963; Ghil et al., 2008). Hence, the ensemble spread gives information on the uncertainty related to small changes in initial conditions at every time step. Here, we propose an alternative approach to producing an ensemble of meteorological conditions for AD 1781-1785. However, it must be remembered that the ensemble spread does not represent the full uncertainty of the reconstruction if the input data are marred with biases, as is also the case for reanalyses (Krueger et al., 2013).

The motivation for our study stems from the climatic conditions that prevailed during and after the eruption of the Icelandic volcano Laki in 1783, one of the largest volcanic 
eruption of the last millennium. To summarize the observed sequence of events, Laki started to erupt in June 1783 and 10 eruption episodes followed until February 1784 (Thordarson and Self, 2003), releasing large amounts of $\mathrm{SO}_{2}, \mathrm{HCl}$, and HF into the atmosphere. Those events killed one third of the population in Iceland (Stone, 2004). The volcanic sulfate aerosols and gases (sulfur and acids) were reported to travel to continental Europe in the days and weeks that followed the eruptions (Thordarson and Self, 2003). Such sulfate aerosols are believed to have triggered respiratory diseases and increased mortality rates in Europe (Desaive et al., 1972; Garnier, 2009a; Schmidt et al., 2011). It is probable that volcanic gases also affected public health (Durand and Grattan, 1999; Grattan et al., 2003; Witham and Oppenheimer, 2004). Modelling studies of the tropospheric chemistry transport have suggested that the environmental and health impact of Laki was connected to dry deposition of sulfate dioxide rather than sulfuric acid (Stevenson et al., 2003).

From a climate point of view, historians have reported that the summer of 1783 had been unusually warm in western Europe (Garnier, 2009b) and the eastern USA, although this warmth was not felt in eastern Europe or central Asia (Thordarson and Self, 2003). The winter of 1783/1784 has been reported to be particularly cold in western Europe and eastern USA (Le Roy Ladurie, 2006; Franklin, 1784; Brazdil et al., 2010). This cold winter had sometimes been associated with the Laki eruption in spring (Wood, 1992; Brazdil et al., 2010). D'Arrigo et al. (2011) have compared the winter in 2009/2010, which had a record of cold in North America and extremely cold in Europe, to the 1783/1784 winter, from proxy reconstructions of the North Atlantic Oscillation (NAO) and the Niño 3 indexes. They conclude that although the atmospheric circulation and temperature patterns were probably similar, it is difficult to attribute a volcanic cause to the cold winter in 1783/1784.

On 20 March 2010, the Icelandic volcano Eyjafjallajökull erupted. On 14 April 2010, the eruption became phreatomagmatic generating an ash plume $10 \mathrm{~km}$ high. The volcanic ash wreaked havoc in air transport, due to the presence of volcanic ash that travelled into continental Europe. Although the style of volcano was different from Laki, it is interesting to investigate whether the atmospheric circulation conditions in spring 2010 were similar to those in spring 1783. If this is the case, one could first guess how volcanic aerosols and gases in 1783 could have been transported into Europe by considering the well-observed circulation variables in 2010, with the hypothesis that the volcanic eruptions and concomitant atmospheric circulation are uncorrelated.

The goal of this paper is to propose an ensemble of meteorological reconstructions around the North Atlantic from a gridded data set of sea-level pressure that was obtained from early instrumental observations. This reconstruction is built on a technique of flow analogues that has been used in various contexts to analyse the atmospheric circulation (Lorenz, 1969; Zorita and von Storch, 1999; Vautard and Yiou, 2009).
Our analysis relies on a data set of daily sea-level pressure obtained by Kington (1988). This data set covers the period between 1781 and 1785 and has a regular grid. We use a methodology of windowed pressure analogues (Yiou et al., 2013) to infer sea-level pressure, temperature and wind fields over the North Atlantic. Such unknown fields of the past are reconstructed from a historical sea-level pressure (SLP) data (Kington, 1988) to search for analogue fields in the NCEP reanalysis (Kalnay et al., 1996). The data and methodology are described in Sect. 2.

We shall estimate the meteorological conditions that prevailed after the Laki volcanic eruption in 1783, although we do not model the transport of volcanic gases and aerosols. Hence, we investigate whether the atmospheric circulation of North Atlantic region during the spring of 2010 was similar to the one in spring 1783 . Then we re-examine the similarity between the winters of 1783/1784 and 2009/2010 in Europe. The results of the SLP, temperature and wind speed reconstructions from analogues are given in Sect. 3. In this section, we also compare the temperature reconstructions with observed temperatures in western Europe. Discussion and conclusion appear in Sect. 4.

\section{Data and methods}

\subsection{Historical period}

We used the gridded SLP data set of Kington (1988) as our target, or predictor reconstruction set. This data set is based on $\approx 70$ early instrumental records from several stations across Europe, from the French Société Royale de Médecine (SRM), the Societas Meteorologica Palatina of Mannheim (SMP), and private archives (Kington, 1988, p. 23). The stations mostly cover France $(\approx 45$ stations $)$, Prussia $(\approx 10$ stations), and Great Britain $(\approx 18$ stations), with a few stations in Iceland (3), Scandinavia (6), Spain (6) and northern Italy (4). Those data sets contain surface pressure, temperature and wind records. The original surface pressure data underwent unit corrections and were converted to SLP by heuristic corrections accounting for estimates of temperature (Kington, 1988). Pressure patterns were then constructed by "drawing isobars in accordance with pressure readings and wind reports, so as to produce a realistic air-flow pattern" (Kington, 1988, p. 26). In addition, "synoptic continuity in the movement and development of pressure systems and fronts [were] taken into account from chart to chart". Thus, the original spatial data were drawn like weather maps from pressure and wind speed readings. The maps were digitized and cast on a regular grid $\left(5^{\circ}\right.$ by $\left.5^{\circ}\right)$ covering the eastern North Atlantic (P. D. Jones, personal communication, 2013). This shows the subjective nature of the data set. Overcoming this caveat requires major efforts that are beyond the scope of this paper, although certainly valuable. Figure S2 in the Supplement illustrates the data coverage of this data set. 
The data cover the period between 1 January 1781 and 30 November 1785 , on a daily timescale. The region covered by this data set is $\left(30^{\circ} \mathrm{W}-30^{\circ} \mathrm{E}, 35-70^{\circ} \mathrm{N}\right)$. This data set was used by studies of the climate impact of the Laki eruption in 1783 (Thordarson and Self, 2003; Schmidt et al., 2011; Oman et al., 2006).

We performed a quality check of the Kington (1988) data in order to remove outliers and errors in dating codes. We hence verified visually that the data file we used in this paper conforms to the maps published by Kington (1988). Many homogeneity issues can affect the original data on which this set is built (Peterson et al., 1998; Caussinus and Mestre, 2004). Those issues include potential changes in instruments, location and surroundings. Assessing the homogeneity of this data set is out of the scope of this paper, but this issue is a caveat of the study. The methodology to produce the gridded data set from station data can also induce biases that are difficult to constrain.

For verification purposes, we used observed surface temperature time series in 10 locations in Europe, covering the Laki period. The altitudes of measurements are not always available and are assumed to be near the surface. Although quality checks of the time series were performed, their homogeneity is less constrained than for periods after 1850, when meteorological networks started to thrive in Europe.

The French station data (Dijon, La Rochelle, Montmorency and Saint-Malo) come from the French Société Royale de Médecine registers. The meteorological observations organized by the Royal Society were recorded by the correspondents in specially printed forms for recording the daily reports in monthly sets. Cotte (1774) was involved with establishing and maintaining an extensive network of weather stations for the society. He gave information about how to make daily instrumental observations in his Traité de Météorologie and similar instructions on instrumental exposure, observational procedure, and methods of recording and summarizing the daily reports were issued by the Royal Society so as to ensure that standardized and comparable observations would be made by the team of correspondents. The original manuscripts containing daily observations have been preserved in the archives of the Académie de Médecine's library. The book of Cotte (1774) and the registers of daily observations can be downloaded at meteo.academie-medecine.fr.

The other European station data (Bologna, Copenhagen, Mannheim, Munich, Prague and Rome) were extracted from the Ephemerides of the Societas Meteorologica Palatina of Mannheim 1781-1792. These publications contain the daily meteorological observations and can be downloaded at bibliotheque.meteo.fr.

The outdoor temperature was observed and recorded three times a day at all stations at 7, 14 and $21 \mathrm{~h}$. The thermometer was to be mounted outside in a sheltered north-facing exposure, in order to record air-shade temperature (Kington,
1988). The thermometer was of the mercury-in-glass pattern, and graduated in degrees Réaumur.

We computed daily averages of temperatures, which could be biased if data are available for the morning or the evening. An average seasonal cycle was computed from those daily time series, and then removed to the daily means. Monthly means of the anomalies were then computed for the 10 locations. The original digitized times series can be downloaded at http://www-lscedods.cea.fr/estimr/CHEDAR/DATA/. The correlations between the individual daily anomalies are indicated in Table S1 in the Supplement.

\subsection{Reanalysis data}

The base predictand data set for our study is the NCEP reanalysis (Kalnay et al., 1996) between 1948 and 2012 on a daily timescale. We used the SLP, near-surface temperature (at $1000 \mathrm{hP}$ height), and wind speed at 1000 and $500 \mathrm{hPa}$ for the climate reconstructions. The reanalysis data were extracted over the North Atlantic region $\left(80^{\circ} \mathrm{W}-30^{\circ} \mathrm{E}, 30\right.$ $70^{\circ} \mathrm{N}$ ), interpolated on a spatial grid of $2.5^{\circ}$ by $2.5^{\circ}$. For comparison purposes with the Kington data set, the NCEP SLP was regridded by averaging onto the Kington grid (smaller domain and lower spatial resolution). The effect of the spatial resolution is illustrated in the Supplement movie (the caption of the movie in provided in the Supplement).

We also computed reconstructed fields for surface temperature and surface wind speed from the NCEP data. We computed daily anomalies of surface temperature and wind speed by subtracting an averaged daily seasonal cycle over 19712000. A land-sea mask was used to estimate continental surface temperature, especially over France.

\subsection{Flow analogues}

We use the methodology and terminology of Yiou et al. (2013) to obtain atmospheric reconstructions based on analogues of atmospheric circulation. This type of approach was also proposed by Schenk and Zorita (2012) in a different context. A general goal of the method of analogues is to reconstruct an ensemble of meteorological fields (e.g. temperature, wind speed, geopotential height) from observations of sealevel pressure. For each day in 1781-1785, the simple form of the analogue method determines the days in 1948-2012 (in the NCEP reanalysis) that minimize a Euclidean distance (or root mean square: RMS) to those of 1781-1785. Since all the meteorological 3-D fields are known in a reanalysis data set, one can infer "analogues" for those fields in the predictor period 1781-1785. Contrary to the simple example of Yiou et al. (2013), the predictand and predictor data sets cover very different periods of time and yield different spatial resolutions. As explained by Yiou et al. (2013), this approach raises an important temporal continuity issue, because the dates of analogues in the predictand set are not necessarily consecutive (or even close to each other). 
In order to reconstruct time continuous sequences, the analogues were computed on moving windows of 5 days. This means that for each sequence of 5 consecutive days between 1781 and 1785, we determine the $N=20$ sequences of 5 days in NCEP that are closer in terms of RMS (Yiou et al., 2013). The quality of the $N$ analogues in the NCEP reanalysis "reference" predictand set is estimated a posteriori by their Spearman spatial correlations (von Storch and Zwiers, 2001) with the predictor SLP field of Kington (1988). Hence, the RMS is optimized on 5-day sequences, and the correlation score is computed on daily reconstructions.

The choice of the window length is a tradeoff between the regularity of the the reconstruction (hence avoiding too many strong discontinuities in the dates of analogues) and quality of the analogues (in terms of correlation). This choice can be guided by the temporal persistence of atmospheric structures. Synoptic structures generally have an average persistence of a few days. We assessed this persistence by estimating the autocorrelation observed in the Kington SLP data set. For each grid point, we computed the autocorrelation function of SLP, with lags between 1 and 20 days (Fig. 1). The median autocorrelations drop within 9 days to an asymptotic value near $C=0.18$. We bootstrapped the dates in the SLP data set in order to obtain confidence intervals for the "background" autocorrelation of the data set. We find that a lag of 5 days is the longest window for which more than $75 \%$ of the grid points yield positive autocorrelations, and more than $10 \%$ of the grid points are below the background autocorrelation. This provides a heuristic way of justifying a window length of $W=5$. The analogues with a window length of $W=1$ day give better correlation values (median $r \approx 0.82$ ) than for $W=5$ (median $r \approx 0.64$ ) but do not have a temporal continuity (see Fig. S3 in the Supplement). For verification purposes, the same procedure was applied to the NCEP reanalysis "predictand" data set (Fig. S1 in the Supplement). The asymptotic value of the autocorrelation median is $C \approx 0.30$, which is not statistically significant from the one obtained with the Kington (1988) data set.

The fields corresponding to the dates of the 20 analogues allow us to make three-dimensional reconstructions of the atmospheric flow and temperature for that period. The reconstruction is performed on weighted moving windows of $W=5$ days shifted by increments of $\delta=2$ days, in order to obtain a temporal continuity of the fields, as argued by Yiou et al. (2013). This weighting procedure is performed for each of the 20 analogues: for example, we take the $k$ th analogues of all 5-day windows covering the predictor period and compute moving averages with weights that are proportional to the time distance to the centre of the window. This produces 20 reconstructions from the windowed analogues. Each analogue reconstruction can be viewed as a possible trajectory of the climate system that is coherent with SLP conditions. Note that each day in an analogue reconstruction is a weighted average of two moving windowed analogues.

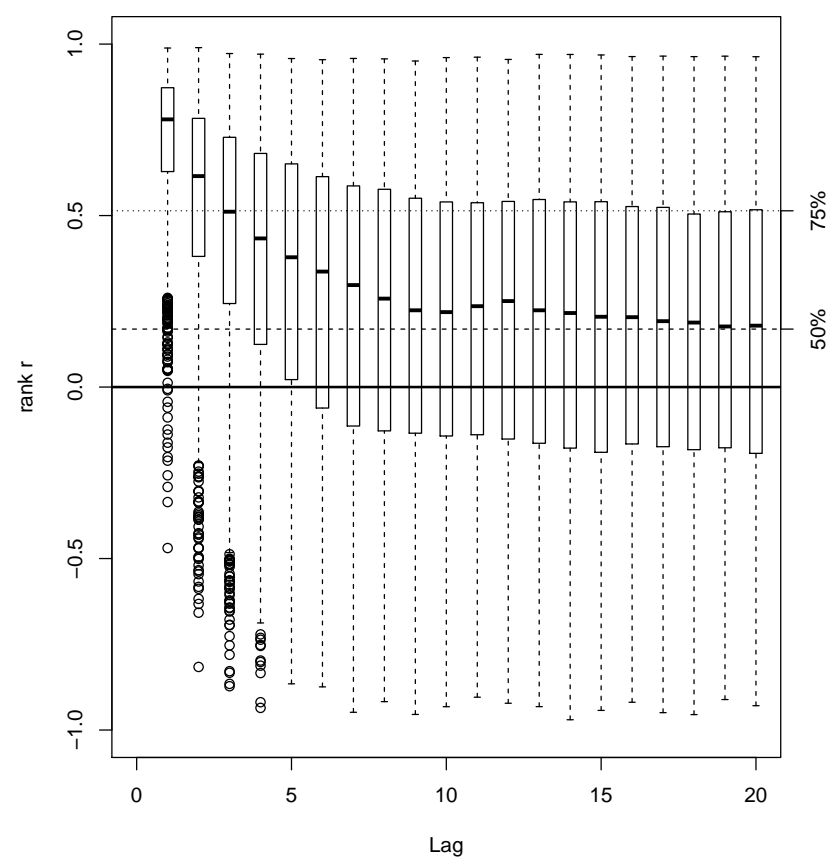

Fig. 1. Distribution of autocorrelation functions for each grid point in the Kington (1988) SLP data set, for lags between 0 and 20 days. Each box and whisker plot is drawn for a lag and all grid points with data. The boxes represent the median $\left(q_{50}\right)$, 25th $\left(q_{25}\right)$ and 75th $\left(q_{75}\right)$ quantiles of the distribution. The upper whisker is $\min \left(1.5\left(q_{75}-q_{25}\right)+q_{50}, \max (C)\right)$; that is, circles are outliers exceeding the interquartile range. The lower whisker is $\max \left(-1.5\left(q_{75}-q_{25}\right)+q_{50}, \min (C)\right)$. The horizontal dashed line represents the 50th quantile of autocorrelation values when days are picked at random. The horizontal dotted line is the 75th quantile of autocorrelation values for days picked at random.

As stated above, the Kington (1988) original time series are on European land (including Iceland). The gridded data set actually contains many cells where there are no data. The computation of analogues is done on a subregion of the predictor maps (i.e. over $5 \times 5$ cells with no missing data). Then the analogues in the predictand set (NCEP reanalysis) are considered on their original $2.5 \times 2.5$ resolution over the whole North Atlantic.

In this paper, we chose to reconstruct anomalies of SLP, surface temperature and surface wind speed. The anomalies are determined with respect to the 1971-2000 reference period. The reason for not reconstructing absolute fields, rather than anomalies, is that we do not have $30 \mathrm{yr}$ climatologies during the 18th century for all fields (apart from SLP and surface temperature).

This statistical approach to meteorological reconstructions complements reanalysis initiatives over long periods (Compo et al., 2011). Rather than running a climate model that assimilates SLP, we compute analogues of SLP and determine the corresponding atmospheric fields in a reference data set (here the NCEP reanalysis). Although the reconstruction yields 

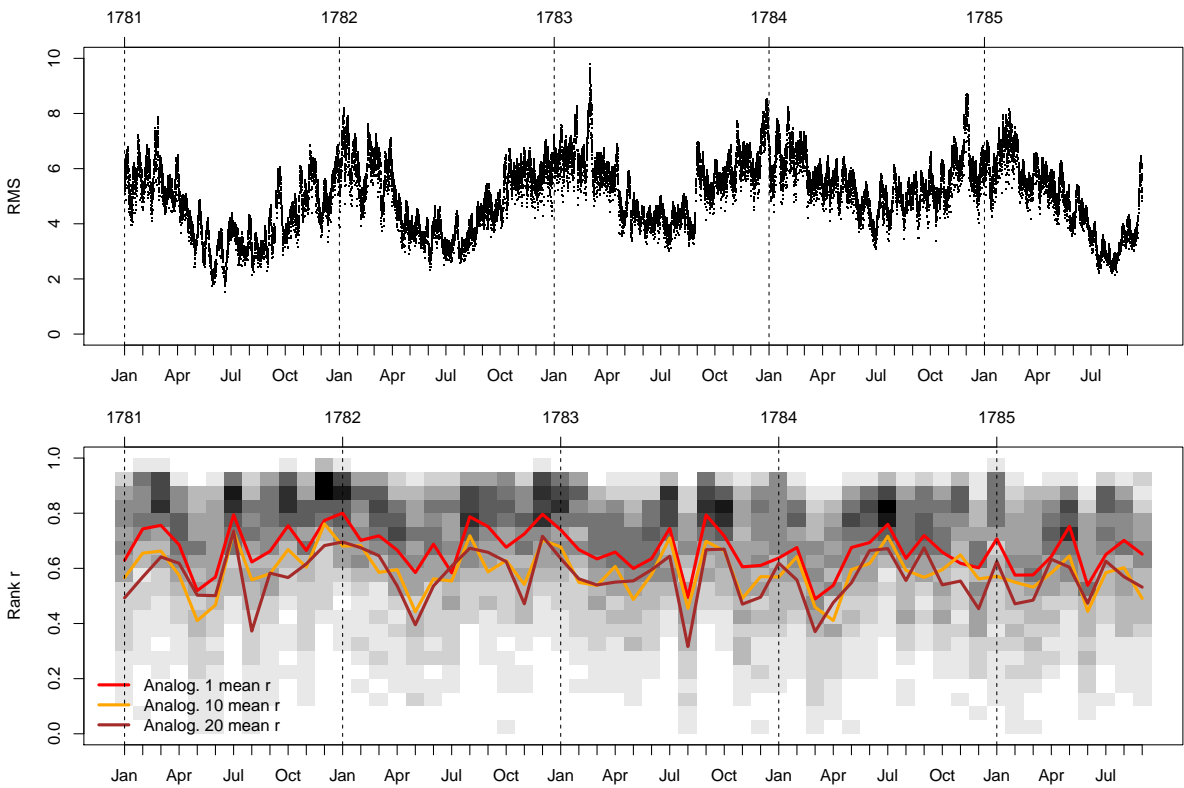

Fig. 2. Scores (correlation and RMS) of analogues. Upper panel: RMS values between Kington (1988) SLP anomalies and analogues in NCEP, between 1781 and 1785 for each day and all 20 analogues. Each day yields 20 dots (one for each analogue). Lower panel: monthly averages of spatial rank correlation between the Kington (1988) SLP anomalies and 20 best analogues from RMS (lines). The shaded squares represent the probability distribution of the correlation values (dark greys indicate higher probability) for each month, for 20 analogues and daily reconstructions. The red line represents the monthly mean of Spearman correlations between the first (i.e. with lowest RMS) analogue and the Kington SLP anomalies. The orange and brown lines represent mean score values for the 10th and 20th analogues (median and worst RMS among the 20 analogues).

poorer scores than what can be obtained by a climate model simulation, we are able to produce relatively large ensembles of conditions at a low computational cost. We also emphasize that the quality of the reconstruction depends on the predictor data set (here the Kington, 1988 set), and the reconstructed ensemble samples the uncertainty due to the analogue method itself.

\section{Results}

\subsection{SLP analogues}

The SLP reconstruction is compared to the predictor data set of Kington (1988) with a resolution of $5^{\circ}$ by $5^{\circ}$. We show the scores of the $N=20$ analogue reconstructions. RMS and correlation values for daily SLP anomalies are shown in Fig. 2 for each day between 1 January 1781 and 30 September 1785, and for each analogue. The RMS values exhibit a seasonal cycle, with higher values in winter and lower in summer. The reason for this seasonal cycle is the seasonality of SLP variance in the extratropics, which is higher in winter than in summer.

The correlation values are on average above $r=0.7$. We computed the empirical probability distribution of the correlation $r$ of the $N$ analogues and the predictor SLP (shadings in Fig. 2). The probability distribution is computed for each month, from the values of the daily correlations of the $N=20$ analogues. We show that SLP analogues that are optimized for RMS can yield very low spatial correlation values (sometimes below 0.4), although the distribution is centred above 0.7 (red line). This is further illustrated in the Supplement movie comparing the predictor data set and the reconstructions from the daily 1 st and 10th analogues, between 1783 and 1784. As shown on this illustration, the analogues are optimized over a relatively small proportion of the eastern North Atlantic and European region (because the Kington, 1988 is mainly based on land data), but the inferred circulation patterns cover the North Atlantic. The summers of 1783 and 1784 are the ones with the highest average RMS values (Fig. 2). During those two summers, we find that the analogue reconstructions can yield rather different behaviours and hence low correlation values with the predictor SLP data set.

The climate trajectory of the atmospheric circulation between 1781 and 1785 can be tracked by the dates of the 20 best analogues in the NCEP reanalysis (between 1948 and 2012). In this way, we assess which years of the predictand data set (NCEP) resemble those of the predictor data set. This computation is done on a monthly timescale: for each day in a month (in 1781-1785), we determine the dates of the 20 best analogues in the predictand set (in 1948-2012), in order to obtain the sample probability distribution of having 
analogues for year of the predictand set. For a given day in 1781 to 1785 , duplicate years are removed. This avoids a potential bias when several analogues fall within the same year: for example, if the 20 analogues of a given predictor day fall on nearby days from the same predictand year, but this predictand year never appears in the analogues of the other days of the predictor month, this would put an unwanted weight on that year. Then, for each predictor month (between January 1781 and October 1785), we count the number of occurrences of daily analogue years. A given year in the NCEP reanalysis is picked five times on average in the SLP analogues, for the whole period. Unusual frequency of a year in the SLP analogues (higher than 90th percentile) reaches 12 days in a month. We focus on the period encompassing the Laki eruption (1 May 1783 to 30 April 1784) (Fig. 3).

We find that the year 2010 is frequently picked in the analogues of May 1783 (Fig. 3), but this is before the Laki eruption. From June to the end of 1783, the frequency of the year 2010 in the analogues never reaches a 90th quantile, and is below the median quantile of frequencies, apart from July, August and December 1783. This implies that the atmospheric circulation of spring 2010 is unlikely to be similar to spring 1783, which witnessed the Laki eruption.

The SLP analogues start to be picked in 2010 in a significant way in October 1783. As suggested in Fig. 3, we verified that, from December 1783 to February 1784, the analogue dates are picked between November 2009 and January 2010 in a high proportion (i.e. above the 90th percentile). This can be interpreted by a high correlation between the atmospheric circulation during the winters 1783/1784 and 2009/2010. The latter winter yielded an anomalous negative phase of the North Atlantic Oscillation (Cattiaux et al., 2010; Cohen et al., 2010; D'Arrigo et al., 2011) and underwent extremely cold and snowy conditions.

In order to estimate the robustness of the result of the analogues of circulation to the reanalysis data set, we made the same exercise with the 20CR reanalysis (Compo et al., 2011). This recent reanalysis data cover 1871 to 2012 . We used an SLP field interpolated on a $2^{\circ} \times 2^{\circ}$ grid. Then we performed the same processing as for the NCEP reanalysis. We find very similar scores for RMS and correlation (Fig. S4 in the Supplement). The distributions of the dates of analogues are different, by construction because the 20CR reanalysis is much longer than NCEP, but we find a qualitative coherence (Fig. S5 in the Supplement) although the differences could be due to issues that are beyond the scope of this paper (Krueger et al., 2013).

\subsection{Temperature estimates}

In this section, we first focus on the 12-month period that includes the Laki eruption, between May 1783 to April 1784 (Fig. 4). We compute monthly means of the 20 analogues of temperature anomalies (with respect to a 1971-2000 climatology) from the temperature at $1000 \mathrm{hPa}$ in NCEP reanalysis. Then, the 20 analogue means are averaged in order to provide a composite monthly reconstruction of temperature anomalies. For each grid cell and each month, the standard deviation of the 20 analogue reconstructions of temperature anomalies is computed. We verify that $80 \%$ of the values of the standard deviations range between 0.2 and $0.9 \mathrm{~K}$, which is small compared to the range of inferred temperature variations ( -4 to $4 \mathrm{~K})$.

We find warm temperature conditions in May 1783 (right before the first Laki eruption, on 8 June 1783) over western Europe and southern Greenland. This warm temperature anomaly intensifies over western Europe until August 1783. It remains positive until October 1783. This warm anomaly is consistent with the historical records for France and some parts of western Europe (Le Roy Ladurie, 2006).

The temperature anomaly over Europe becomes negative and increasingly cold between November 1783 and February 1784. This cooling is also found in the northeastern US, although not as intense as in Europe. We note that the western Arctic remains anomalously warm. The cold European and North American cold anomaly is also evidenced by historical records in Europe (Le Roy Ladurie, 2006) and the USA (Franklin, 1784).

The time series of the analogue temperature reconstruction for France between 1781 and 1785 is shown in Fig. 5. The monthly mean of the 20 analogue reconstructions shows the warm anomaly in the summer of 1783 followed by the cold winter anomaly. In this very short time series (less than $5 \mathrm{yr}$ ), only 1783 and 1784 yield such a large temperature swing between a warm summer and cold winter in France. This shows that the temperature anomalies are controlled by the circulation anomalies.

We compared the analogue temperature anomaly reconstruction with early meteorological observations in France and Europe, between 1781 and 1785. The data are monthly averaged for 10 stations (Fig. 6). The correlations between the median of 20 analogue reconstructions and the observed series exceeds $r=0.42$ (with $p$ values lower than $5 \times 10^{-3}$ ) for all cities except Bologna, Rome and Dijon. The temperature observations yield a larger variance than the average reconstruction over France. This is due to the spatial averaging in Fig. 5. We also compare the station temperature anomalies with the nearest grid cell in the analogue reconstructions.

The warm anomaly in France in the summer 1783 is well reproduced by the analogue reconstruction. The amplitude of the following winter anomaly is weaker and lags by 2 months. The other periods of the reconstructions yield much weaker amplitudes than the observations, although the correlations are significantly positive. One caveat of this comparison is that the homogeneity of the observed temperature times series is barely verified. For example, it has been documented that the thermometer used for La Rochelle record was changed in 1782, from a Sigaud de Lafond thermometer to a Mannheim thermometer (meteo.academie-medecine.fr), whose features could have been different. 

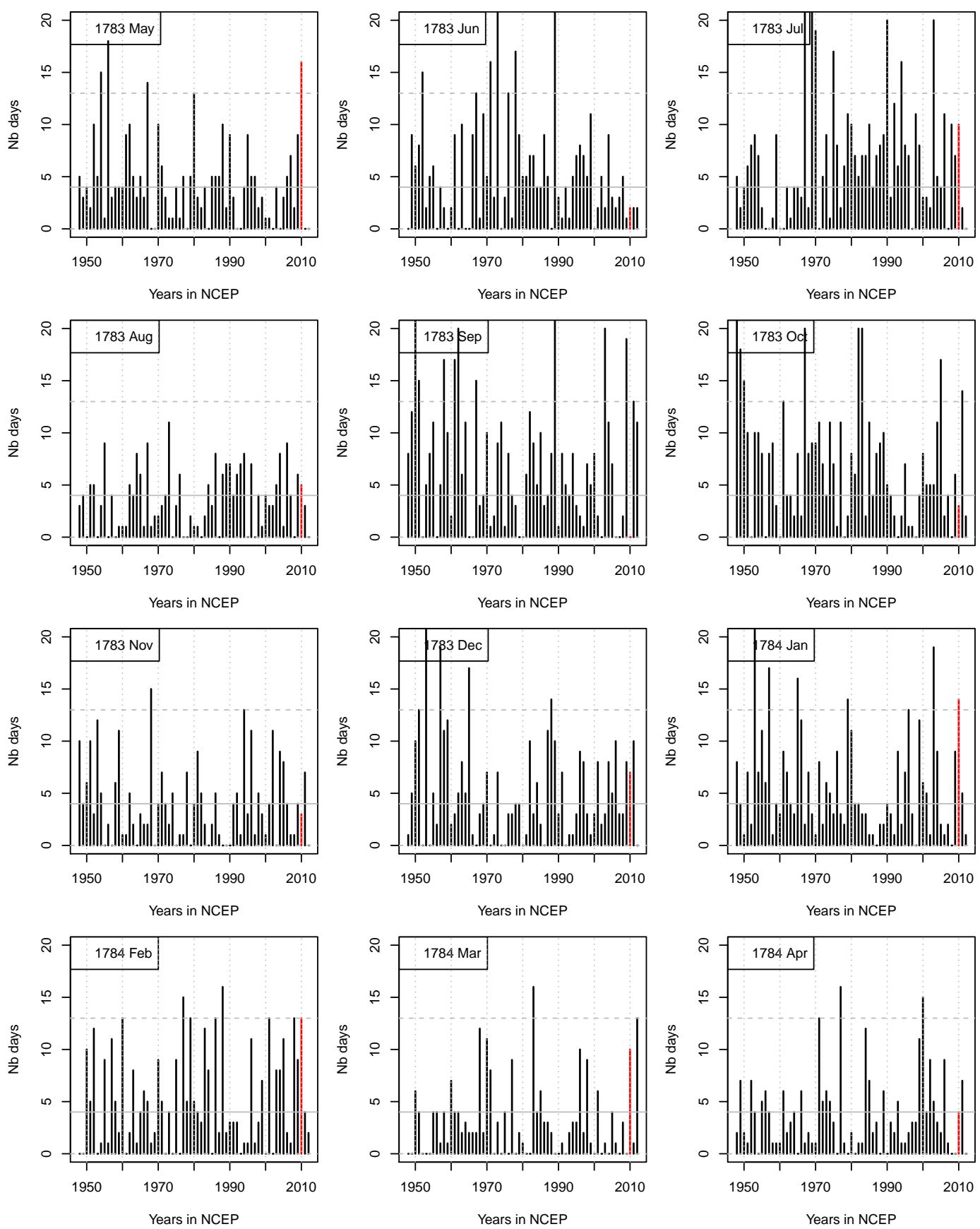

Fig. 3. Histograms of years of the 20 first analogues (between 1948 and 2012), for the months between May 1783 and April 1784 . The 2010 year is outlined in red. The horizontal grey lines represent the median frequency of the years of analogues. The horizontal dashed lines are the 10th and 90th quantiles of the frequency of the years of analogues.

The reconstructed temperature anomaly fluctuations over France are coherent with historical chronicles between 1781 and 1785 (Le Roy Ladurie, 1971, 2006; Garnier, 2009b). These historical qualitative compilations (partly based on diaries and crop/harvest yields) suggest this sequence of warm summers and cold winters during those 5 years.
This result suggests that the atmospheric circulation played a major role in the summer temperature variation in 1783. This role seems less clear in the years that precede and follow the Laki eruption. But this conclusion should be moderated by the low number of observations before 1783 . 
Temperature anomalies (post 178305)
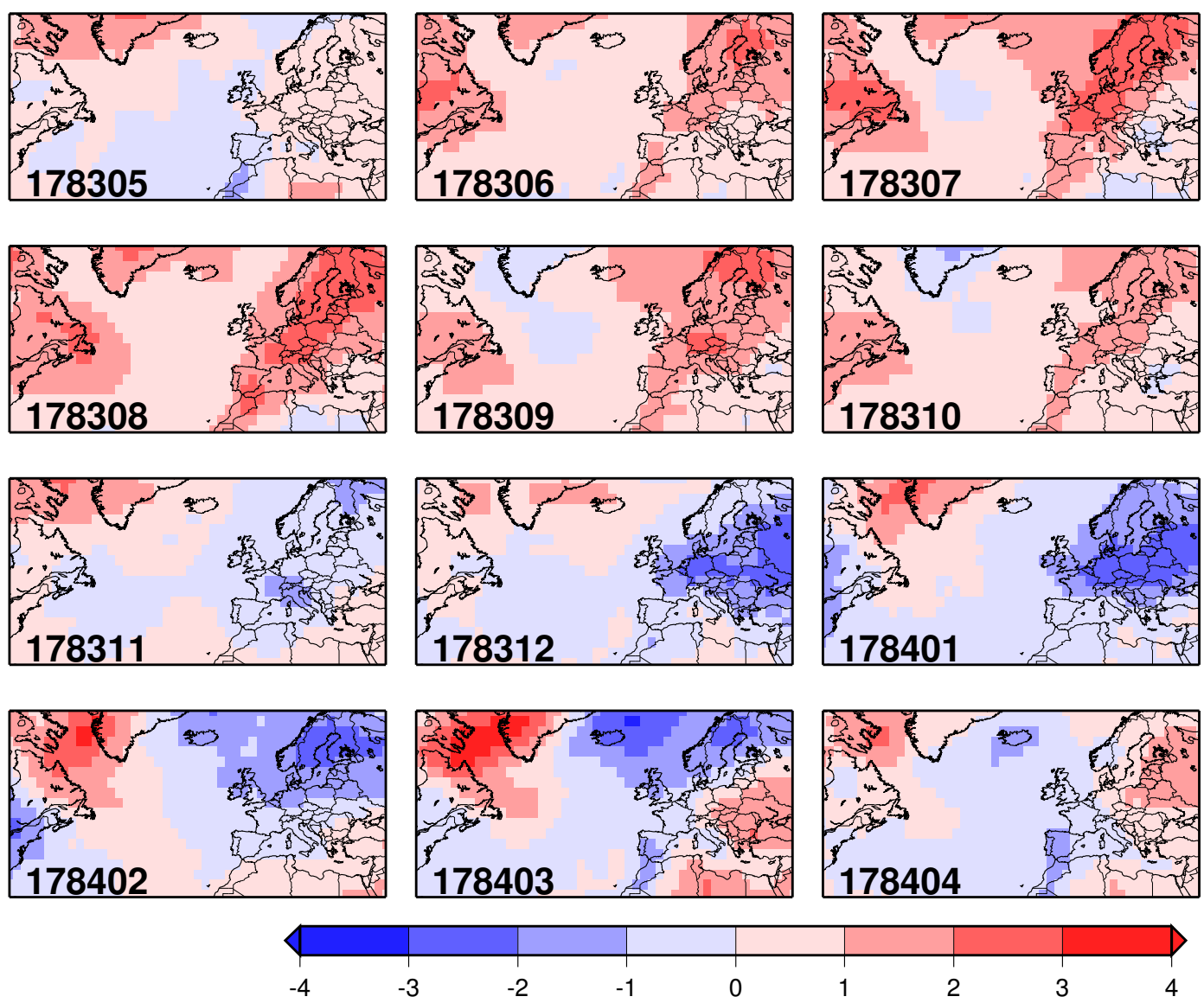

Fig. 4. Median of 20 surface air temperature anomaly reconstructions (in K) with respect to 1971-2000, between May 1783 and April 1784. The months are indicated in the lower left corners of the panels as $10^{2} y+m$, where $y$ and $m$ are respectively the year and the month.

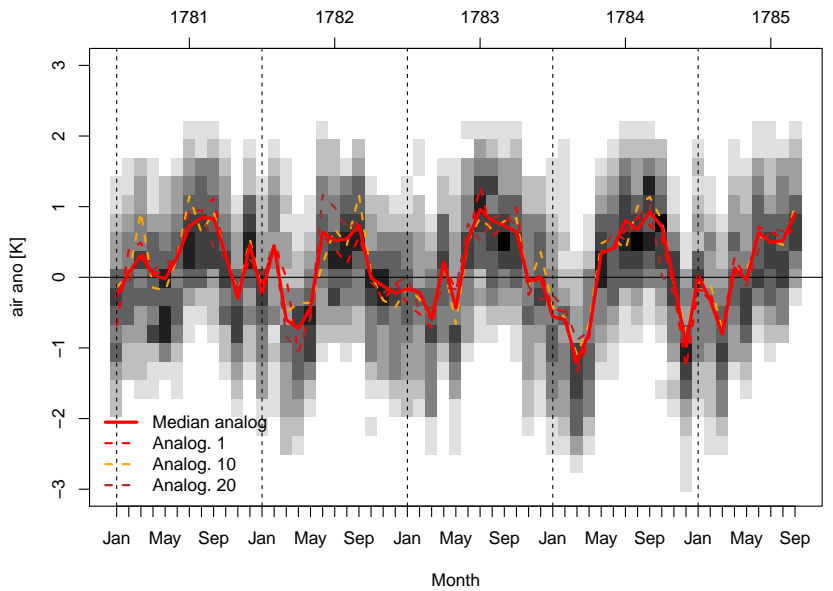

Fig. 5. Median of 20 surface air temperature anomaly reconstructions for France in 1783-1784 (red line, in K). The grey squares represent the monthly probability distribution of the 20 analogue reconstructions.
For comparison purposes, we performed the same exercise of analogue search for the winter of 2009/2010. We computed the analogues of circulation from the NCEP reanalysis, interpolated on the Kington (1988) grid, with the years 2009-2010 as predictors, and $1948-2000$ as predictand. The median of the temperature analogues exhibits the cold spell that was witnessed in northern Europe from December 2009 to February 2010, as already shown by Cattiaux et al. (2010) (Fig. S6 in the Supplement). We also find that the anomaly of temperature in the winter $1783 / 1784$ did not reach as cold temperatures as those observed (or reconstructed) in 2009/2010

\subsection{Wind estimates}

We computed 1000 and $500 \mathrm{hPa}$ wind anomaly reconstructions from SLP analogues for the 12 months following the first Laki eruption (Figs. 7 and 8). Such anomalies are superimposed over a generally northeastward flow. The wind anomaly reconstructions in May and July 1783 do not seem favourable to an optimal transport of air masses from Iceland to continental Europe. The conditions in June, August and 

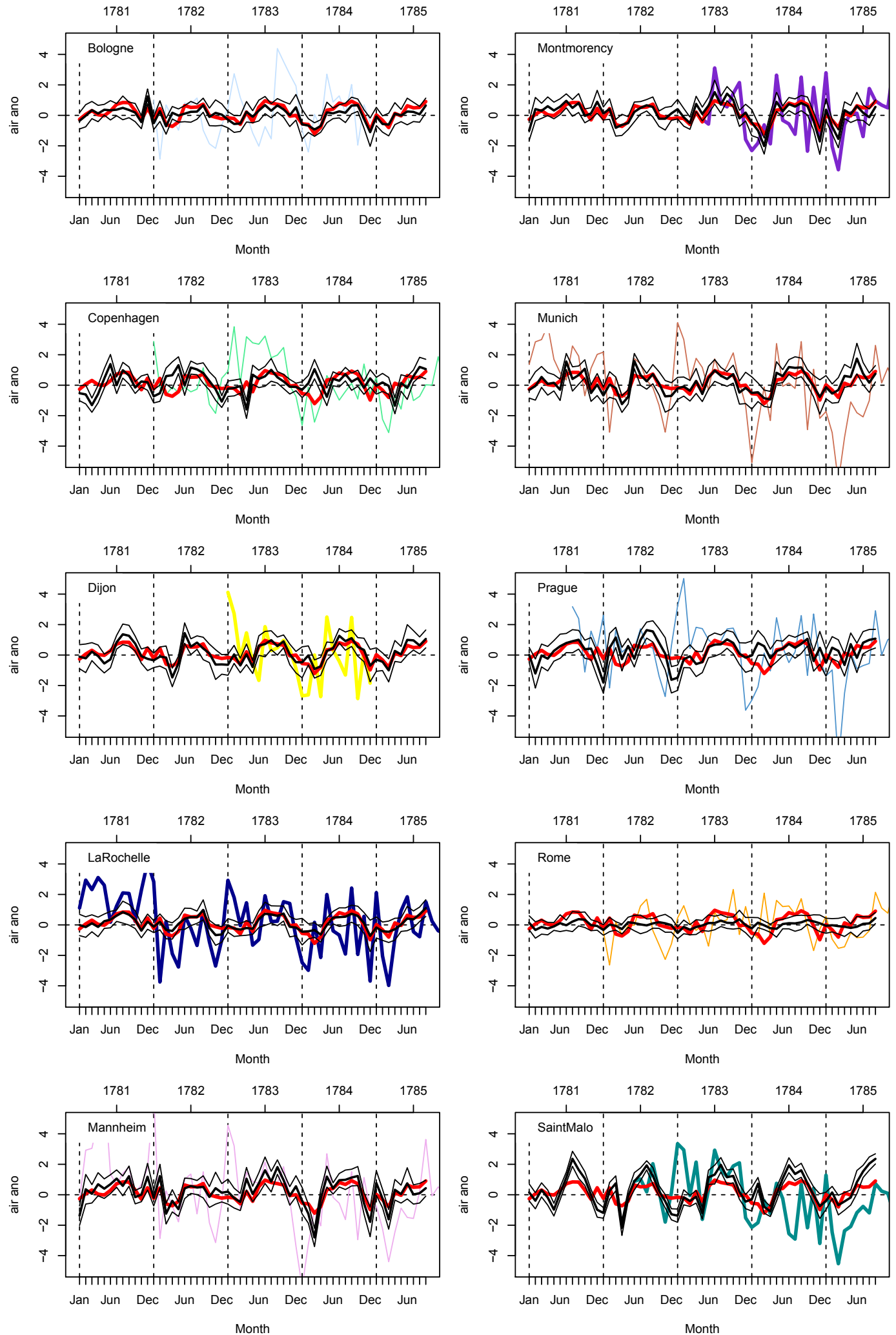

Fig. 6. Monthly temperature anomalies in Europe from historical records (in K) with respect to an average seasonal cycle (continuous coloured lines). The thick black lines represent the temperature anomaly reconstructions for the grid cell closest to the indicated historical record. The thin black lines indicate the $\sigma$ interval around the reconstruction. The red thick lines represent the average of the temperature anomaly reconstruction over France (same line for all panels). 
$1000 \mathrm{hPa}$ Wind anomalies (post 178305)
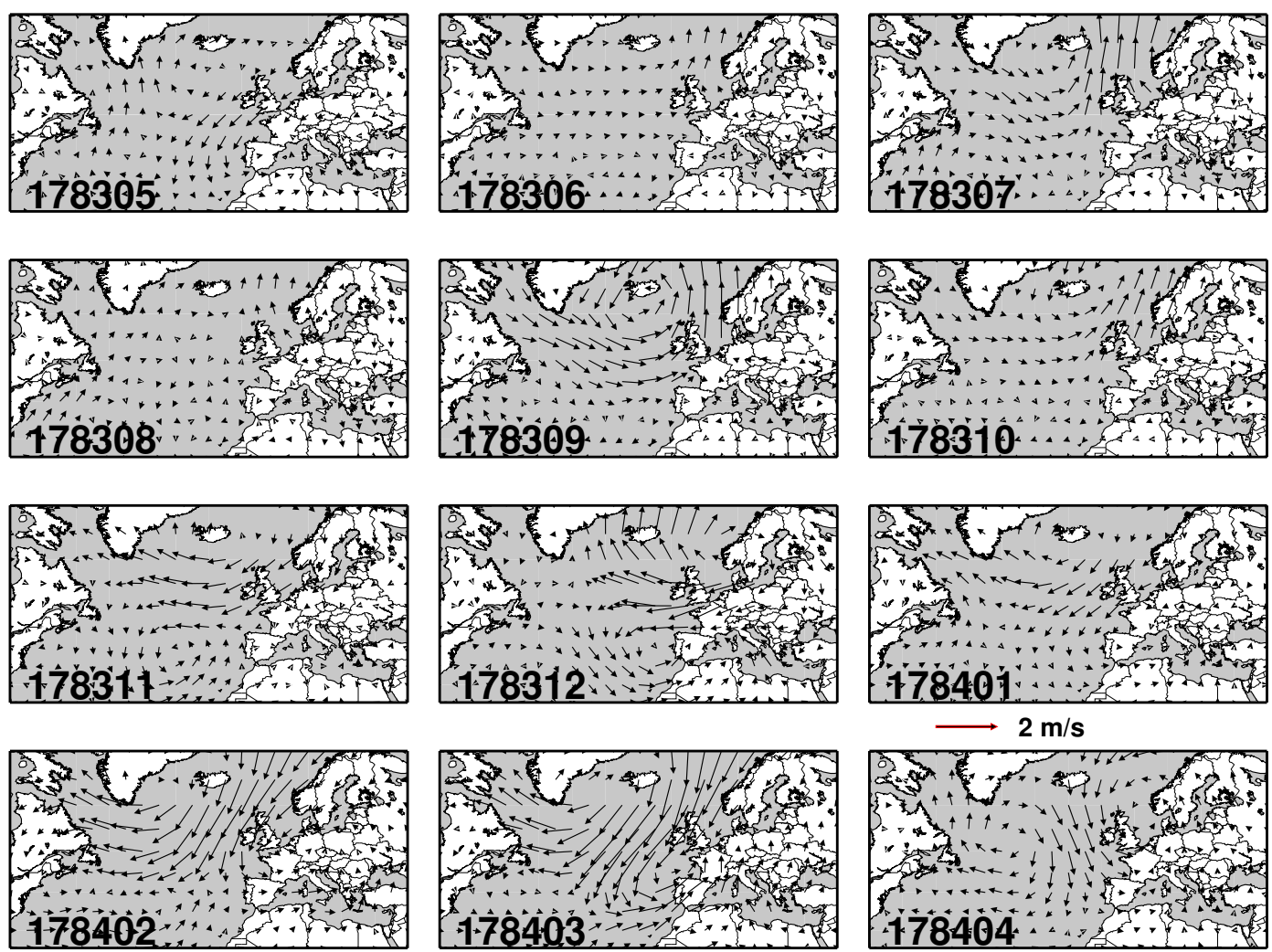

Fig. 7. Anomalies of wind speed at $1000 \mathrm{hPa}$ between May 1783 and April 1784. The red horizontal arrow indicates the wind speed scale (in $\mathrm{m} \mathrm{s}^{-1}$ ).

September seem more favourable to transport from Iceland to western continental Europe. This is coherent with the early observations of Mourgue de Montredon (1783), as pointed out by Chenet et al. (2005).

The northward flow over the northeastern US explains the warm temperatures that were reconstructed there. The reconstructed wind field over the Labrador region does not explain how volcanic gases from Laki could be transported directly to the eastern US. As found in the experiments of Chenet et al. (2005), our reconstructed field suggests a route around Greenland and the Arctic region.

The winter wind anomaly reconstruction at $1000 \mathrm{hPa}$ indicates anticyclonic circulations conveying cold air from the Arctic to western continental Europe, between November 1783 and February 1784. This explains the cold temperature anomalies reconstructed in Fig. 4.

\section{Discussion and conclusions}

We have proposed an ensemble of atmospheric reconstructions for temperature and flow conditions that is compatible with an estimate of sea-level pressure between 1781 and 1785 . We find that the atmospheric variability explains a significant part of the observed temperature in Europe $(r>0.4$ over France, Germany and Denmark). In particular, we find that the very warm summer and cold winter in Europe and eastern US, after the Laki eruption, can be explained by the atmospheric circulation variability. This result is robust to the 20 analogue trajectories, which all correspond to this warm to cold temperature oscillation.

We emphasize that only anomalies of meteorological variables have been reconstructed by this method. In principle, the absolute values of pressure-related fields can be reconstructed with this method, because the analogues can be constrained by the absolute values. The absolute fields like temperature can be obtained once a background climatology is determined. This can be done from monthly reconstructions (Luterbacher et al., 2002; Jacobeit et al., 2003) during the 18 th century or a contemporary climatology (from a reanalysis), so that the differences can be very large. This means that the temperature inference is qualitative (or else strong hypotheses need to be formulated).

The results on temperature reconstructions are coherent with historical and proxy records in Europe, especially during the Laki eruption period. D'Arrigo et al. (2011) suggested that the winter conditions in 1783/1784 resembled those of the 2009/2010 winter. Our analysis confirms this 
$500 \mathrm{hPa}$ Wind anomalies (post 178305)
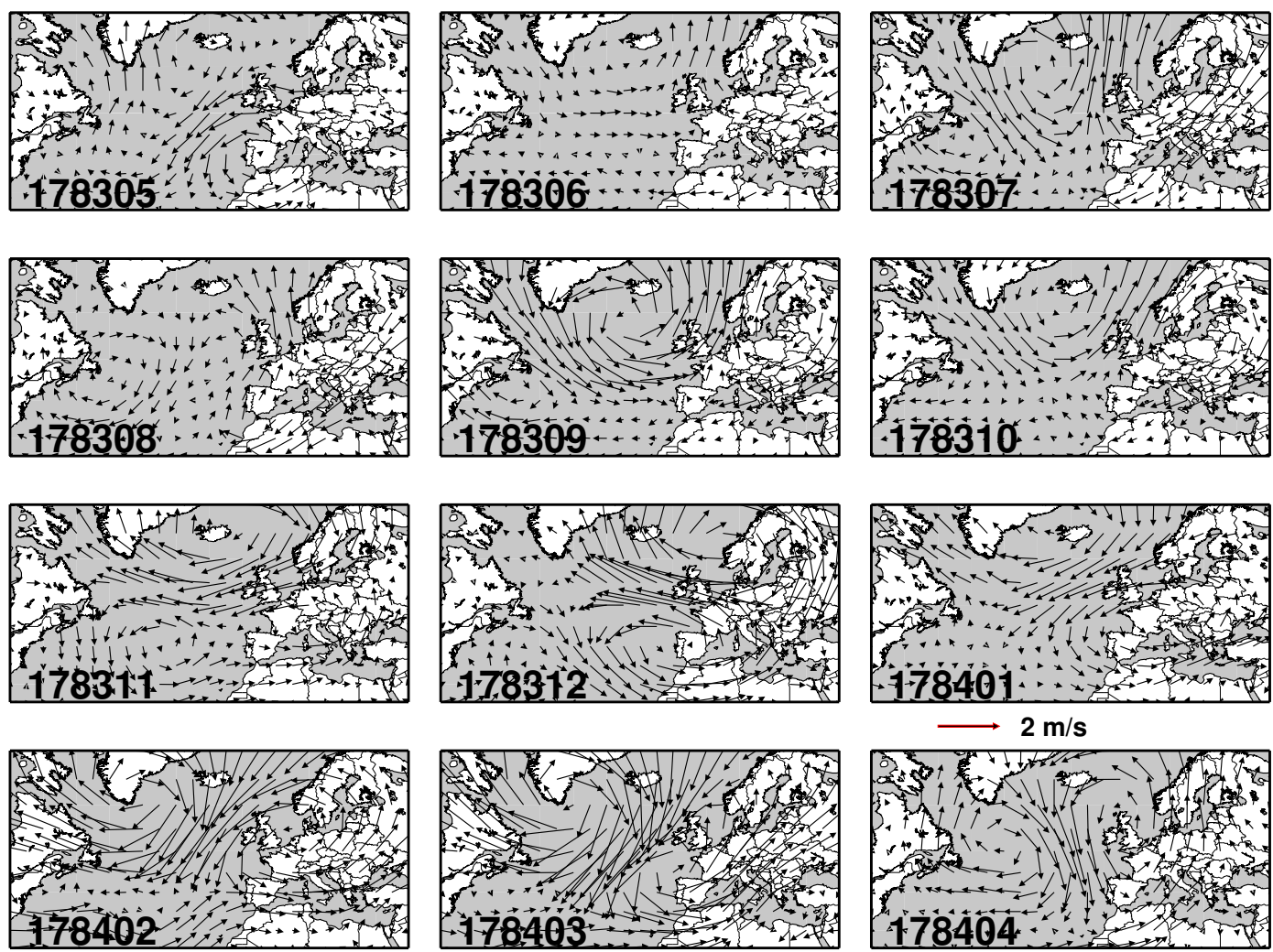

Fig. 8. Anomalies of wind speed at $500 \mathrm{hPa}$ between May 1783 and April 1784. The red horizontal arrow indicates the wind speed scale (in $\mathrm{m} \mathrm{s}^{-1}$ ).

inference, although the $1783 / 1784$ winter was not as cold as 2009/2010, at least in France.

This paper shows that the atmospheric circulation trajectory that led to the cold winter in 1783/1784 does not stem from spring-summer-early autumn conditions in 2009, because the dates of analogues are mostly picked in years other than 2009. The distribution of the dates of analogues shows that even though some years can dominate the analogue distributions, the seasonal variability does not follow a consistent path throughout a year, and there is no link between the spring and following winter atmospheric conditions that could be identified from the dates of analogues. Therefore, if we admit that the winter of 2009/2010 is analogous to the winter of $1783 / 1784$ in terms of atmospheric circulation and temperature, the paths that lead to such conditions were rather different in both cases because the autumn seasons preceding the cold winters of 1783 and 2009 have no striking analogues. Hence we find it unlikely that the the cold winter in 1783/1784 was related to the preceding spring atmospheric conditions, because the intermediate seasons (summer and autumn) in 1783 and 2009 do not resemble each other. This is based on the heuristic conjecture that the same causes should have similar effects.
We have produced an ensemble of analogue reconstructions for SLP, temperature and wind speed over the North Atlantic, with a daily timescale and the spatial resolution of the NCEP reanalysis. Other variables have been produced for instance at various pressure levels (as was tested by Yiou et al., 2013). Those variables include temperatures, geopotential height, wind speed and relative humidity. Such a production can be used to constrain a chemistry transport model in order to investigate the trajectories of volcanic aerosols from Iceland to Europe. Hence we can envisage comparing an ensemble of air-quality model simulations with local observations of respiratory problems that were reported in the summer of 1783. As noted in the introduction, we emphasize that the reconstructed ensemble spread does not represent the uncertainty on the input data set itself (which is difficult to assess) but rather the spread of meteorological conditions that yield analogue SLP patterns.

\section{Supplementary material related to this article is available online at http://www.clim-past.net/10/797/2014/ cp-10-797-2014-supplement.zip.}


Acknowledgements. We thank P. D. Jones for providing the data files for the Kington SLP data and a discussion on its production. We acknowledge Germany's National Meteorological Service (DWD) for providing the images of Ephemerides Societatis Meteorologicae Palatinae. This work was supported by the French ANR CEP project CHEDAR. We thank C. Eschstruth for digitizing some of the historical temperature data. All computations were performed with the $\mathrm{R}$ language (http://www.r-project.org). The two anonymous referees brought many constructive comments that helped clarify the manuscript.

Edited by: E. Zorita

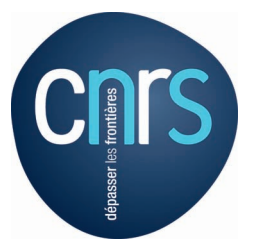

The publication of this article is financed by CNRS-INSU.

\section{References}

Appenzeller, C., Stocker, T., and Anklin, M.: North Atlantic oscillation dynamics recorded in Greenland ice cores, Science, 282, 446-449, doi:10.1126/science.282.5388.446, 1998.

Brazdil, R., Demarée, G. R., Deutsch, M., Garnier, E., Kiss, A., Luterbacher, J., Macdonald, N., Rohr, C., Dobrovolny, P., Kolar, P., and Chroma, K.: European floods during the winter 1783/1784: scenarios of an extreme event during the 'Little Ice Age', Theor. Appl. Climatol., 100, 163-189, doi:10.1007/s00704-009-0170-5, 2010.

Cattiaux, J., Vautard, R., Cassou, C., Yiou, P., Masson-Delmotte, V., and Codron, F.: Winter 2010 in Europe: A cold extreme in a warming climate, Geophys. Res. Lett., 37, L20704, doi:10.1029/2010g1044613, 2010.

Caussinus, H. and Mestre, O.: Detection and correction of artificial shifts in climate series, J. Roy. Stat. Soc. Ser. C, 53, 405-425, doi:10.1111/j.1467-9876.2004.05155.x, 2004.

Chenet, A. L., Fluteau, F., and Courtillot, V.: Modelling massive sulphate aerosol pollution, following the large 1783 Laki basaltic eruption, Earth Planet. Sc. Lett., 236, 721-731, doi:10.1016/j.eps1.2005.04.046, 2005.

Cohen, J., Foster, J., Barlow, M., Saito, K., and Jones, J.: Winter 2009-2010: A case study of an extreme Arctic Oscillation event, Geophys. Res. Lett., 37, L17707, doi:10.1029/2010g1044256, 2010.

Compo, G., Whitaker, J., Sardeshmukh, P., Matsui, N., Allan, R., Yin, X., Gleason, B., Vose, R., Rutledge, G., Bessemoulin, P., Brönnimann, S., Brunet, M., Crouthamel, R., Grant, A., Groisman, P., Jones, P., Kruk, M., Kruger, A., Marshall, G., Maugeri, M., Mok, H., Nordli, O., Ross, T., Trigo, R., Wang, X., Woodruff, S., and Worley, S.: The Twentieth Century Reanalysis Project, Q. J. Roy. Meteorol. Soc., 137, 1-28, doi:10.1002/qj.776, 2011.

Cook, E., D'Arrigo, R., and Briffa, K.: A reconstruction of the North Atlantic Oscillation using tree-ring chronologies from North America and Europe, Holocene, 8, 9-17, 1998.
Cotte, L.: Traité de Météorologie, Imprimerie Royale, Paris, 1774.

D'Arrigo, R., Seager, R., Smerdon, J. E., LeGrande, A. N., and Cook, E. R.: The anomalous winter of 1783-1784: Was the Laki eruption or an analog of the 2009-2010 winter to blame?, Geophys. Res. Lett., 38, L05706, doi:10.1029/2011GL046696, 2011.

Desaive, J., Goubert, J., Le Roy Ladurie, E., Meyer, J., Muller, O., and Peter, J.: Médecins, Climat et Epidémies - la Fin du XVIIème Siècle, Mouton \& Co et Ecole Pratique des Hautes Etudes, Paris, 1972.

Durand, M. and Grattan, J.: Extensive respiratory health effects of volcanogenic dry fog in 1783 inferred from European documentary sources, Environ. Geochem. Health, 21, 371-376, doi:10.1023/A:1006700921208, 1999.

Franklin, B.: Meteorological imagination's and conjectures, Manchester Lit. Philos. Soc. Mem. Proc., 2, 373-377, 1784.

Garnier, E.: Laki : une catastrophe européenne, l'Histoire, 343, 72 77, 2009a.

Garnier, E.: Les dérangements du temps : 500 Ans de chaud et de froid en Europe, Plon, Paris, 2009b.

Ghil, M., Chekroun, M., and Simonnet, E.: Climate dynamics and fluid mechanics: Natural variability and related uncertainties, Physica D, 237, 2111-2126, doi:10.1016/j.physd.2008.03.036, 2008.

Grattan, J., Durand, M., and Taylor, S.: Illness and elevated human mortality in Europe coincident with the Laki Fissure eruption, Volcanic Degassing, 213, 401-414, doi:10.1144/Gs1.Sp.2003.213.01.24, 2003.

Hurrell, J., Kushnir, Y., Ottersen, G., and Visbeck, M. (Eds.): The North Atlantic Oscillation : Climatic Significance and Environmental Impact, in: vol. 134 of Geophysical monograph, American Geophysical Union, Washington, DC, 2003.

Jacobeit, J., Wanner, H., Luterbacher, J., Beck, C., Philipp, A., and Sturm, K.: Atmospheric circulation variability in the NorthAtlantic-European area since the mid-seventeenth century, Clim. Dynam., 20, 341-352, 2003.

Jones, P., Davies, T., Lister, D., Slonosky, V., Jonsson, T., Barring, L., Jonsson, P., Maheras, P., Kolyva-Machera, F., Barriendos, M., Martin-Vide, J., Rodriguez, R., Alcoforado, M., Wanner, H., Pfister, C., Luterbacher, J., Rickli, R., Schuepbach, E., Kaas, E., Schmith, T., Jacobeit, J., and Beck, C.: Monthly mean pressure reconstructions for Europe for the 1780-1995 period, Int. J. Climatol., 19, 347-364, 1999.

Kalnay, E., Kanamitsu, M., Kistler, R., Collins, W., Deaven, D., Gandin, L., Iredell, M., Saha, S., White, G., Woollen, J., Zhu, Y., Chelliah, M., Ebisuzaki, W., Higgins, W., Janowiak, J., Mo, K., Ropelewski, C., Wang, J., Leetmaa, A., Reynolds, R., Jenne, R., and Joseph, D.: The NCEP/NCAR 40-year reanalysis project, B. Am. Meteorol. Soc., 77, 437-471, 1996.

Kimoto, M. and Ghil, M.: Multiple flow regimes in the Northernhemisphere winter, 1. Methodology and hemispheric regimes, J. Atmos. Sci., 50, 2625-2643, 1993.

Kington, J.: The weather of the 1780s over Europe, Cambridge University Press, Cambridge, New York, 1988.

Krueger, O., Schenk, F., Feser, F., and Weisse, R.: Inconsistencies between Long-Term Trends in Storminess Derived from the 20CR Reanalysis and Observations, J. Climate, 26, 868-874, doi:10.1175/Jcli-D-12-00309.1, 2013. 
Le Roy Ladurie, E.: Times of feast, times of famine: a history of climate since the year 1000, Doubleday, Garden City, N.Y., translated by Barbara Bray. illus., facsims., maps. $24 \mathrm{~cm}$, A rev. and updated English version of the author's Histoire du climat depuis l'an mil, originally published in 1967, 1971.

Le Roy Ladurie, E.: Histoire Humaine et Comparée du Climat, Disettes et Révolutions 1740-1860, Fayard, Paris, 2006.

Lorenz, E. N.: Deterministic nonperiodic flow, J. Atmos. Sci., 20, 130-141, 1963.

Lorenz, E. N.: Atmospheric Predictability as Revealed by Naturally Occurring Analogues, J. Atmos. Sci., 26, 636-646, 1969.

Luterbacher, J., Schmutz, C., Gyalistras, D., Xoplaki, E., and Wanner, H.: Reconstruction of monthly NAO and EU indices back to AD 1675, Geophys. Res. Lett., 26, 2745-2748, 1999.

Luterbacher, J., Xoplaki, E., Dietrich, D., Rickli, R., Jacobeit, J., Beck, C., Gyalistras, D., Schmutz, C., and Wanner, H.: Reconstruction of sea level pressure fields over the Eastern North Atlantic and Europe back to 1500, Clim. Dynam., 18, 545-561, 2002

Michelangeli, P., Vautard, R., and Legras, B.: Weather regimes: Recurrence and quasi-stationarity, J. Atmos. Sci., 52, 1237-1256, 1995.

Mourgue de Montredon, M.: Recherches sur l'origine et sur la nature des vapeurs qui ont régné dans l'atmosphère pendant l'été de 1783, Imprimerie Royale, Paris, 1783.

Oman, L., Robock, A., Stenchikov, G. L., Thordarson, T., Koch, D., Shindell, D. T., and Gao, C. C.: Modeling the distribution of the volcanic aerosol cloud from the 17831784 Laki eruption, J. Geophys. Res.-Atmos., 111, D12209, doi:10.1029/2005JD006899, 2006.

Palmer, T. N.: The economic value of ensemble forecasts as a tool for risk assessment: From days to decades, Q. J. Roy. Meteorol. Soc., 128, 747-774, doi:10.1256/0035900021643593, 2002.

Peterson, T. C., Easterling, D. R., Karl, T. R., Groisman, P., Nicholls, N., Plummer, N., Torok, S., Auer, I., Boehm, R., Gullett, D., Vincent, L., Heino, R., Tuomenvirta, H., Mestre, O., Szentimrey, T., Salinger, J., Forland, E. J., Hanssen-Bauer, I., Alexandersson, H., Jones, P., and Parker, D.: Homogeneity adjustments of in situ atmospheric climate data: A review, Int. J. Climatol., 18, 1493-1517, 1998.
Schenk, F. and Zorita, E.: Reconstruction of high resolution atmospheric fields for Northern Europe using analog-upscaling, Clim. Past, 8, 1681-1703, doi:10.5194/cp-8-1681-2012, 2012.

Schmidt, A., Ostro, B., Carslawa, K., Wilsona, M., Thordarson, T., Manna, G., and Simmons, A.: Excess mortality in Europe following a future Laki-style Icelandic eruption, P. Natl. Acad. Sci. 108, 15710-15715, doi:10.1073/pnas.1108569108, 2011.

Souriau, A. and Yiou, P.: Grape harvest dates for checking NAO paleoreconstructions, Geophys. Res. Lett., 28, 3895-3898, doi:10.1029/2001GL012870, 2001

Stevenson, D. S., Johnson, C. E., Highwood, E. J., Gauci, V., Collins, W. J., and Derwent, R. G.: Atmospheric impact of the 1783-1784 Laki eruption: Part I Chemistry modelling, Atmos. Chem. Phys., 3, 487-507, doi:10.5194/acp-3-487-2003, 2003.

Stone, R.: Volcanology - Iceland's doomsday scenario?, Science, 306, 1278-1281, doi:10.1126/science.306.5700.1278, 2004.

Thordarson, T. and Self, S.: Atmospheric and environmental effects of the 1783-1784 Laki eruption: A review and reassessment, J. Geophys. Res.-Atmos., 108, 4011, doi:10.1029/2001jd002042, 2003.

Vautard, R. and Yiou, P.: Control of recent European surface climate change by atmospheric flow, Geophys. Res. Lett., 36, L22702, doi:10.1029/2009GL040480, 2009.

von Storch, H. and Zwiers, F. W.: Statistical Analysis in Climate Research, Cambridge University Press, Cambridge, 2001.

Witham, C. S. and Oppenheimer, C.: Mortality in England during the 1783-4 Laki Craters eruption, Bull. Volcanol., 67, 15-26, doi:10.1007/s00445-004-0357-7, 2004.

Wood, C.: Climatic effects of the 1783 Laki eruption, in: The Year Without a Summer: World Climate in 1816, chap. Climatic effects of the 1783 Laki eruption, edited by: Harrington, C., Can. Mus. of Nat., Ottawa, 58-77, 1992.

Yiou, P., Salameh, T., Drobinski, P., Menut, L., Vautard, R., and Vrac, M.: Ensemble reconstruction of the atmospheric column from surface pressure using analogues, Clim. Dynam., 41, 13331344, doi:10.1007/s00382-012-1626-3, 2013.

Zorita, E. and von Storch, H.: The analog method as a simple statistical downscaling technique: Comparison with more complicated methods, J. Climate, 12, 2474-2489, 1999. 